\title{
Fatty acids in cell signaling: Historical perspective and future outlook
}

Citation for published version (APA):

Glatz, J. F. C., \& Luiken, J. J. F. P. (2015). Fatty acids in cell signaling: Historical perspective and future outlook. Prostaglandins Leukotrienes and Essential Fatty Acids, 92, 57-62. https://doi.org/10.1016/j.plefa.2014.02.007

Document status and date:

Published: 01/01/2015

DOI:

10.1016/j.plefa.2014.02.007

Document Version:

Publisher's PDF, also known as Version of record

Document license:

Taverne

Please check the document version of this publication:

- A submitted manuscript is the version of the article upon submission and before peer-review. There can be important differences between the submitted version and the official published version of record.

People interested in the research are advised to contact the author for the final version of the publication, or visit the DOI to the publisher's website.

- The final author version and the galley proof are versions of the publication after peer review.

- The final published version features the final layout of the paper including the volume, issue and page numbers.

Link to publication

\footnotetext{
General rights rights.

- You may freely distribute the URL identifying the publication in the public portal. please follow below link for the End User Agreement:

www.umlib.nl/taverne-license

Take down policy

If you believe that this document breaches copyright please contact us at:

repository@maastrichtuniversity.nl

providing details and we will investigate your claim.
}

Copyright and moral rights for the publications made accessible in the public portal are retained by the authors and/or other copyright owners and it is a condition of accessing publications that users recognise and abide by the legal requirements associated with these

- Users may download and print one copy of any publication from the public portal for the purpose of private study or research.

- You may not further distribute the material or use it for any profit-making activity or commercial gain

If the publication is distributed under the terms of Article $25 \mathrm{fa}$ of the Dutch Copyright Act, indicated by the "Taverne" license above, 


\title{
Fatty acids in cell signaling: Historical perspective and future outlook
}

\author{
Jan F.C. Glatz*, Joost J.F.P. Luiken \\ Department of Molecular Genetics, Cardiovascular Research Institute Maastricht (CARIM), Maastricht University, P.O. Box 616, \\ 6200 MD Maastricht, The Netherlands
}

\begin{abstract}
A B S T R A C T
Fatty acids are not only important metabolic substrates and building blocks of lipids but are also increasingly being recognized for their modulatory roles in a wide variety of cellular processes including gene expression, together referred to as the 'message-modulator' function of fatty acids. Crucial for this latter role is the bioavailability of fatty acids, which is governed by their interaction with soluble proteins capable of binding fatty acids, i.e., plasma albumin and cytoplasmic fatty acid-binding protein $\left(\mathrm{FABP}_{\mathrm{c}}\right)$, and with both the lipid and protein components of biological membranes, including membraneassociated fatty acid-binding proteins such as the transmembrane protein CD36. Manipulating fatty acid availability holds promise as therapeutic approach for chronic diseases that are characterized by a perturbed fatty acid metabolism.
\end{abstract}

(c) 2014 Elsevier Ltd. All rights reserved.

\section{Introduction}

The first International Round Table on 'Fatty Acids and Cell Signaling' (FACS) was organized by professor Emmanuel A. Nunez and held near Paris, France, in 1992 [1]. The purpose of that meeting was to discuss the physiological and pathological effects of fatty acids beyond their obvious roles as nutrients and as components of complex lipids. Thus, fatty acids themselves can be seen as blood-borne signals that can act upon cells directly. In addition, fatty acids can become more potent or more specific signals after they have been metabolized, the best known examples of which are the prostaglandins. In general, signaling molecules such as fatty acids and their metabolites can merely accelerate or decelerate chemical reactions or specific processes in cells. With respect to fatty acids, of special importance is their ability to amplify, dampen, or modify signals transmitted by e.g. hormones. This is referred to as the 'message-modulator' function of fatty acids.

Fatty acids and related metabolites are excellently suitable as modulators of homeostatic processes. The brevity and limitation of their presence in time and space in the circulation and in cells allows for a precise regulation of biological processes. Therefore, the (bio) availability of fatty acids is a major determinant of their modulatory function, as will be discussed in more detail below. Manipulation of dietary intake of fatty acids, both the amount and type of fatty acids, also has a major impact on the availability of fatty acids and, therefore, on various biological processes in health and disease.

\footnotetext{
* Corresponding author. Tel.: + 31 433881998; fax: + 31433884574

E-mail address: glatz@maastrichtuniversity.nl (J.F.C. Glatz).
}

One of the scientists who early on recognized and subsequently performed pioneering studies on the pivotal role of fatty acids in human physiology is Dr. David F. Horrobin (1939-2003), the founding editor of Prostaglandins, Leukotrienes and Essential Fatty Acids [2]. He became interested after learning that the hormone prolactin stimulates the release of essential fatty acids from cells [3]. Horrobin also was inspired by the work of Dr. Hugh M. Sinclair (1910-1990) on essential fatty acids [4] and believed that many diseases involve a lack of fatty acid precursors and might be treated by supplementing with the appropriate fatty acid [5]. Specifically, Horrobin's work focused on evening primrose oil, which contains $\gamma$-linolenic acid, an essential n- 6 fatty acid that supposedly would alleviate a variety of chronic disease conditions such as breast pain, alcoholism, rheumatoid arthritis, and atopic eczema [6]. He was committed to discovering simple drugs for complex diseases. In addition, he was an advocate of an ambience to express ideas, openly and freely, and for that has helped to create a forum for scientific discussion, amongst others, as founder and editor of scientific journals including Medical Hypotheses and Prostaglandins, Leukotrienes and Essential Fatty Acids. Taken together, Dr. Horrobin has contributed markedly to our current understanding of the extended role of fatty acids in various aspects of the functioning of the human body.

\section{Bioavailability of fatty acids}

The hydrophobic nature of (long-chain) fatty acids dictates specific requirements to their presence and transport in aqueous compartments. In blood plasma and the interstitium fatty acids are 
avidly bound by albumin $(68 \mathrm{kDa})$ or are present as fatty ester in lipoproteins. Intracellularly, fatty acids are bound by cytoplasmic fatty acid-binding protein $\left(\mathrm{FABP}_{\mathrm{c}} ; 15 \mathrm{kDa}\right)$, which acts as the intracellular counterpart of plasma albumin. The FABPs are members of the intracellular lipid-binding protein (iLBP) family and comprise at least nine distinct types each showing a specific tissue distribution pattern [7-9]. Some FABPs not only bind long-chain fatty acids but also selected other lipids such as eicosanoids, bile salts, lyso-phospholipids, and compounds that act as peroxisome proliferators.

Albumin and the FABPs each bind (long-chain) fatty acids with such high affinities that virtually all of the fatty acids present in the aqueous compartment are protein-bound. Thus, in plasma and interstitium the total fatty acid concentration is $100-400 \mu \mathrm{M}$ while the concentration of non-protein bound fatty acids is several orders of magnitude lower and amounts to only 1-10 nM (Fig. 1) $[10,11]$. Similarly, for hepatocytes and cardiomyocytes it has been estimated that in the soluble cytoplasm the total fatty acid concentration is up to $50 \mu \mathrm{M}$ (depending on the metabolic state of the cell) while the non-protein bound fatty acid concentration is only 1-5 nM $[12,13]$. As a result, albumin and cytoplasmic FABP each provide a buffer for fatty acids, as each fatty acid that is metabolized or undergoes transmembrane transport to another compartment is immediately replenished by the release of another fatty acid from the protein binding site. It should be emphasized that the abundance of albumin in plasma and interstitium (300$600 \mu \mathrm{M})$ and that of FABP in the soluble cytoplasm $(150-300 \mu \mathrm{M}$ in hepatocytes and cardiomyocytes) presents with a total buffering capacity that markedly exceeds the total fatty acid concentration in each compartment (Fig. 1). The latter assures that the nonprotein bound fatty acid concentration remains low, even under mild pathological conditions (e.g. mild ischemia), so as to keep fatty acids from exerting potential detrimental effects [13].

With respect to the cellular uptake of fatty acids, albumin acts merely as a large-capacity buffer for non-protein bound fatty acids while cytoplasmic FABP functions as a sink for incoming fatty acids. Studies with genetically manipulated mouse models have shown that cytoplasmic FABP displays a permissive action (rather than a regulatory role) in cellular fatty acid uptake. Thus, in skeletal muscle of mice with an homozygous deletion of hearttype FABP, the fatty acid uptake rate was reduced by $42-45 \%$ while in skeletal muscle from heterozygous mice, in which the FABP protein expression was $34 \%$ of that of wild-type mice, fatty acid uptake was not altered compared to that in wild-type animals [14]. As a result, cytoplasmic FABP plays an important, yet permissive, role in fatty acid uptake into muscle.

\section{Control of cellular fatty acid uptake at the plasma membrane}

In the past there has been considerable debate on the mechanism by which fatty acids traverse the plasma membrane to enter the soluble cytoplasm [15]. The dispute centered around the ratelimiting kinetic step in this process and whether one or more membrane proteins could facilitate and/or regulate the overall uptake process. When considering the cellular uptake of fatty acids, the physical transport can be regarded to comprise (i) entry of the fatty acid into the outer leaflet of the lipid bilayer, whereby the hydrocarbon chain intercalates between the chains of the phospholipid and the carboxyl group localizes at the aqueous interface (adsorption), (ii) translocation of the fatty acid to the inner leaflet, whereby the polar carboxyl group moves through the bilayer interior and re-positions at the opposite interface ('flip-flop'), and (iii) movement of the fatty acid into the intracellular aqueous phase and its hydration (desorption). Detailed biophysical studies have disclosed that the fatty acid adsorption step and the subsequent flip-flop of fatty acids in a phospholipid bilayer are very fast for virtually all fatty acid types, but that desorption from the membrane will be the rate-limiting step of transmembrane transport [16]. Fatty acid desorption also is strongly dependent on chain length and degree of unsaturation of the fatty acid [17]. For dietary fatty acids measured values of desorption kinetics have revealed half-life times in the $\mathrm{ms}$ to $\mathrm{s}$ range, which would be fast enough to support intracellular metabolism [17]. Based on these findings it was concluded that the lipid bilayer of the plasma membrane does not represent a barrier for fatty acids and that, therefore, cellular fatty acid uptake can occur by (passive) diffusion without the need for membrane proteins to facilitate the process [16].

From a theoretical perspective it would be undesirable to have fatty acids pass biological membranes without control. Indeed, several membrane-associated fatty acid-binding proteins have been identified and shown to be involved in the fatty acid uptake process. Interestingly, these membrane proteins, often referred to as 'fatty acid transporters', function not only in facilitating but also in regulating fatty acid entry into the cell. This is currently viewed to occur by adsorbing fatty acids from the extracellular media, modulating their transport into and across the membrane, and segregating or organizing fatty acids for subsequent intracellular transport and metabolism [18]. Furthermore, one of these fatty acid transporters, i.e., CD36, was found to regulate fatty acid uptake in muscle by a mechanism that resembles that of GLUT4mediated cellular glucose uptake. Thus, following an acute stimulus

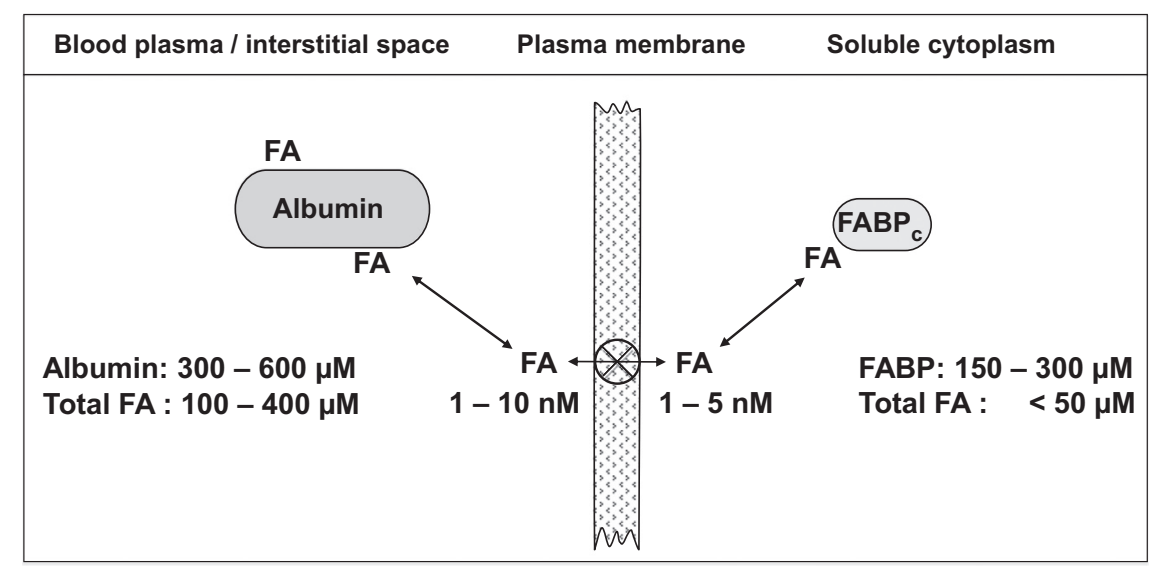

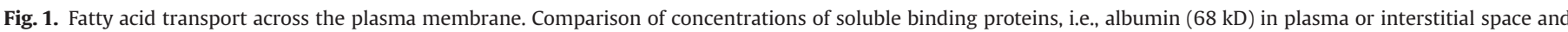

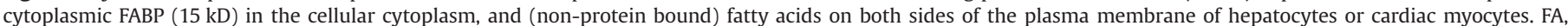
long-chain fatty acid; FABP, fatty acid-binding protein. 


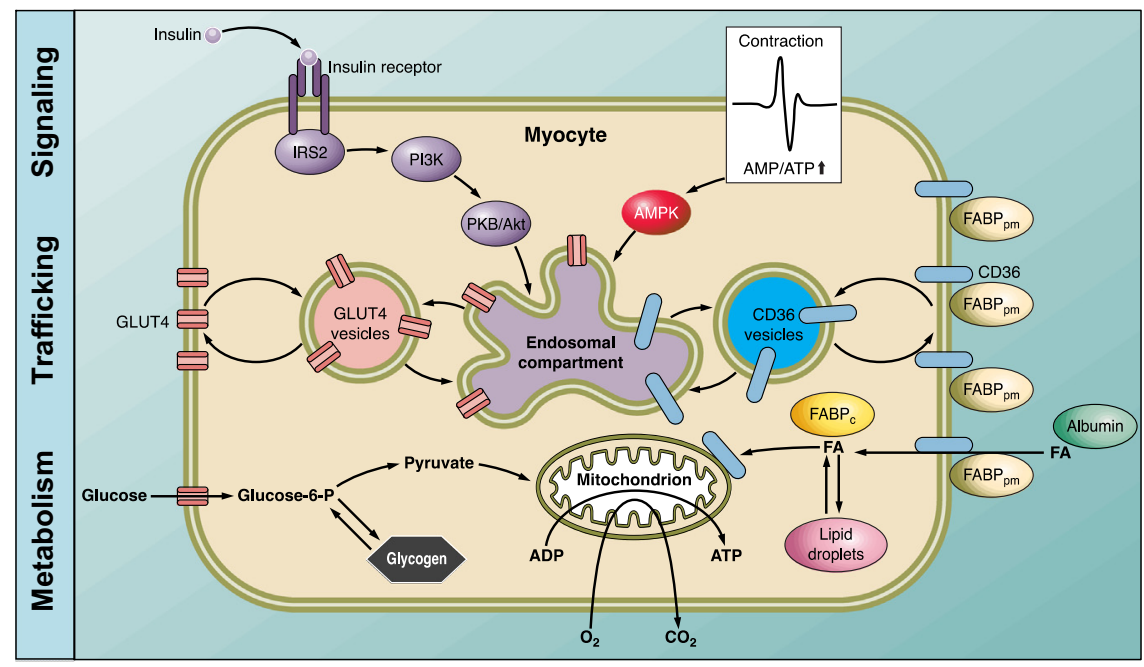

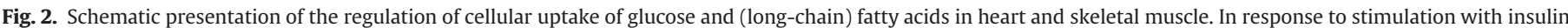

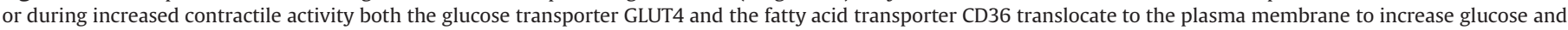

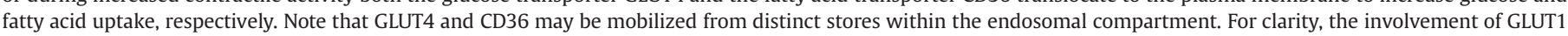

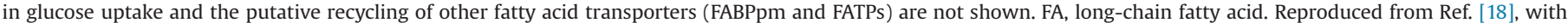
permission.

(insulin, muscle contraction) CD36 translocates from an intracellular store (endosomes) to the plasma membrane (Fig. 2). This recycling of CD36, together with the similar recycling of the glucose transporter GLUT4, appears to be pivotal for the proper regulation of cellular substrate uptake, for instance to clear lipids from the circulation postprandially and to rapidly facilitate substrate provision when the metabolic demands of muscle are increased by contractile activity [18]. Recent data indicate that this function of CD36 is controlled not only by intracellular recycling but also by post-translational modification, in particular $N$-glycosylation [19] and ubiquitination $[20,21]$.

At the extracellular site CD36 shows protein-protein interaction with plasma membrane fatty acid-binding protein (FABPpm), a peripheral membrane protein of ca. $43 \mathrm{kD}$ with a ubiquitous tissue occurrence [22], and at the intracellular site with cytoplasmic FABP that will bind the incoming fatty acids and facilitate their transport to sites of utilization as discussed above [8]. While FABPpm has been shown to facilitate cellular fatty acid uptake [23], the precise nature of this role is still obscure [7]; for instance, it may function to help create a local high concentration of fatty acids to drive their uptake or to localize CD36 to domains of the plasma membrane where fatty acid uptake preferentially would occur. Interestingly, a family of so-called 'fatty acid-transport proteins' (FATP; $63 \mathrm{kD}$ ) has been identified [24], consisting of 6 members (FATP1-6) each displaying a characteristic tissue distribution. The FATPs are trans-membrane proteins showing acyl-CoA synthetase activity and merely function in the uptake of very long-chain fatty acids (chain length $>22$ ) which then are converted directly into very long-chain acyl-CoA esters [18,24].

With the disclosure of the regulatory role of membraneassociated proteins - particularly CD36 - in cellular fatty acid uptake, a discussion was started on the rate-limiting step of the overall process of cellular fatty acid utilization. In liver, heart and skeletal muscle, carnitine palmitoyl-transferase-I (CPT-I) is wellestablished to provide a major site of acute regulation of fatty acid $\beta$-oxidation via its physiological inhibitor malonyl-CoA. The enzymatic activity of CPT-I is generally proposed to be the overall ratelimiting step in long-term cellular fatty acid utilization, at least in heart, muscle and liver [25]. However, recent work has questioned this role for CPT-I. Specifically, partial inhibition of CPT-I activity in vivo in rats, induced by subjecting the animals to daily injections with etomoxir, a specific inhibitor of CPT-I, for 8 days and resulting in a $44 \%$ reduced cardiac CPT-I activity, failed to alter the rates of cardiac long-chain fatty acid uptake and/or oxidation [26]. These data indicate that CPT-I does not act as a major ratecontrolling site in total cardiac fatty acid flux, and suggest that cellular fatty acid uptake (trans-sarcolemmal transport) is the primary site of fatty acid flux regulation. The recent finding that the major changes in substrate preference (glucose versus fatty acids) occurring during cardiac ischemia and reperfusion are associated with coordinated changes in the sarcolemmal presence of the respective transporter proteins (GLUT4 and CD36, respectively) provides further evidence for this concept [27].

\section{Manipulating fatty acid availability and therapeutic approach}

Several chronic diseases such as cardiovascular and neurodegenerative diseases with genetic and lifestyle components (e.g., dietary factors) are characterized by a perturbed fatty acid (lipid) metabolism. An example that currently receives world-wide attention is the so-called metabolic syndrome, defined as a clustering of multiple metabolic abnormalities based on central obesity and insulin resistance. The significance of the metabolic syndrome is its close association with the risk of type 2 diabetes and cardiovascular disease. Obesity is characterized by disturbances in the control of glucose and fat metabolism which is associated with an atherogenic lipid profile in blood and with deleterious fat accumulation in non-adipose tissues like liver, heart, and muscle (ectopic fat deposition). As a consequence, individuals suffering from these abnormalities are at high risk for developing cardiovascular complications, including stroke, myocardial infarction, and kidney failure [28]. Further understanding of the regulation of whole body lipid metabolism, its perturbations in obesity and insulin-resistance, and the cause of this cascade of adverse events eventually leading to cardiovascular disease, is expected to help design strategies to prevent (e.g., lifestyle intervention) and treat this chronic metabolic disorder. Below, two examples are discussed of therapeutic approaches that focus on manipulating fatty acid availability.

The cytoplasmic FABPs found in adipocytes and macrophages, i.e., A-FABP (FABP4) and E-FABP (FABP5), act at the interface of metabolic and inflammatory pathways. These FABPs exert a 
dramatic impact on obesity, insulin resistance, type 2 diabetes, fatty liver disease, atherosclerosis and asthma [29]. It has been suggested that pharmacological agents with the ability to modify FABP function may provide tissue-specific or cell-specific control of lipid signaling pathways, inflammatory responses and metabolic regulation. Recently, Hoo et al. [30] reported studies on the inhibition of A-FABP as potential treatment of non-alcoholic steatohepatitis (NASH) in mice. Specifically, mice subjected to either lipopolysaccharide (LPS)-induced acute liver injury or to high fat high cholesterol diet-induced obesity and non-alcoholic fatty liver disease showed a significantly elevated A-FABP expression in Kupffer cells. Treatment of mice with BMS309403, a specific A-FABP inhibitor, led to both a diminished LPS-induced liver injury and a diminished diet-induced obesity, hepatic steatosis and macrophage infiltration [30]. These observations indicate not only the pivotal role of A-FABP in both LPS-induced acute liver injury and diet-induced NASH, but also illustrate the potential of pharmacological inhibition of cytoplasmic FABP as modality for metabolic diseases.

CD36 has been implicated in the etiology of high fat dietinduced lipid accumulation in ectopic tissues such as heart and skeletal muscle. In turn, an increased cardiac and muscular lipid content has been associated with pathophysiological conditions, in particular insulin resistance and diabetic cardiomyopathy [31,32]. In these tissues, lipid accumulation occurs as a result of a high fat dietinduced re-location of CD36 from intracellular stores (endosomes) to the plasma membrane, without a change in the total cellular content of CD36 [18,33]. The increased amount of CD36 on the plasma membrane elicits an increased rate of fatty acid uptake exceeding the mitochondrial $\beta$-oxidation rate and thus leading to an increased storage of fatty acids into triacylglycerols and an increased production of bio-active metabolites such as diacylglycerols and ceramides. The latter interfere with GLUT4-mediated glucose uptake thereby causing insulin resistance [34] and eventually contractile dysfunction [33]. Studies by Angin and co-workers [35] on isolated cardiomyocytes subjected to insulin-resistance evoking conditions (medium with high palmitate concentration) have shown that immunochemical inhibition of CD36 prevents lipid accumulation, insulin resistance and contractile dysfunction. These studies suggest that pharmacological CD36 inhibition may be considered as a treatment strategy to counteract impaired functioning of the lipid-loaded heart [36]. In line with these findings, Geloen et al. [37] described the identification of low molecular mass chemicals that can block the lipid binding and uptake functions of CD36 to subsequently show that these CD36 inhibitors reduce postprandial hypertriglyceridemia and protect against diabetic dyslipidemia and atherosclerosis in rodents. Similarly, Bessi et al. [38] reported that pretreatment of mice with EP 80317, a selective synthetic peptide ligand of $\mathrm{CD} 36$, protected the heart against damage and dysfunction elicited by myocardial ischemia and reperfusion.

\section{Health benefits of specific fatty acids}

On the basis of epidemiological studies specific fatty acid species have been found to exert beneficial effects to human health. Perhaps the best known example of this is the efficacy of omega-3 long-chain polyunsaturated fatty acids (n-3 LC-PUFA) in preventing and/or treating several metabolic pathologies [39]. Numerous randomized-controlled intervention trials have been published in which the efficacy of either fish consumption or supplementation with marine oils or with selected fatty acid species from these sources - in particular eicosapentaenoic acid (EPA, 20:5 n-3) and docosahexaenoic acid (DHA, 22:6 n-3) - on prevention and treatment of chronic disease was investigated. The available evidence suggests that n-3 LC-PUFAs might improve some features of the obesity-associated metabolic syndrome such as insulin resistance, hypertension, and dyslipidemia, by decreasing the plasma triacylglycerol concentration. Moreover, because of their blood pressure-lowering and anti-inflammatory properties, n-3 LC-PUFAs might act as cardioprotective agents [40]. In view of these beneficial actions of $n-3$ LC-PUFAs, health organizations have established recommendations for their dietary intake.

In this context, the work of Dr. Alexander Leaf (1920-2012) on the prevention of sudden cardiac death by n-3 LC-PUFAs should be mentioned [41]. Dr. Leaf examined the anti-arrhythmic properties of polyunsaturated fatty acids starting from molecular and cellular studies, progressing to animal models, and finally to a clinical trial, using a variety of techniques. In animal studies he showed that the protective effect of n-3 LC-PUFAs results mainly from the modulation of ion channels and stabilization of the electrical activity of cardiomyocytes [42]. Subsequently, these findings were validated in a clinical trial showing that the n-3 LC-PUFAs in fish oils can reduce fatal ventricular arrhythmias in high-risk patients [43]. However, clinical studies performed by other investigators revealed inconsistent results with one study even reporting possible adverse, i.e., pro-arrhythmic, effects of fish oil supplementation [44]. Taken together, the notion arises that despite the anti-arrhythmic effect of n-3 LC-PUFAs documented in various cellular and animal studies, clinical studies have not (yet) supported this mode of action [40]. These differences in outcome may relate to, for instance, different doses or concentrations of n-3 LC PUFAs used in the various studies, the applicability of the beneficial effects only to specific patients groups, to the interaction of n-3 LC-PUFAs with specific medication received by the patients under study, or that other fish-oil constituents play a significant role. With respect to the latter, it has been speculated that longchain fatty alcohols might exert beneficial health effects [45].

The health beneficial effects of fatty acids may relate not only to polyunsaturated fatty acids as several recent analyses indicate that saturated fatty acids, particularly in dairy products and coconut oil, can improve health [46]. The shorter chain (C4-C12) fatty acids found in milk fat and coconut oil, in particular lauric acid (dodecanoic acid, 12:0), are held responsible for these beneficial effects. Shorter chain saturated fatty acids are metabolized more rapidly and were found to have antiviral, antimicrobial, antitumor, and immune response functions [47].

\section{A fatty view of the future}

Fatty acids serve essential roles in many aspects of human functioning. In fact, it has become increasingly difficult to find (patho)physiological processes in which fatty acids do not play important, if not central, roles as signaling and modulatory molecules. This even includes a role for fatty acids in epigenetic gene regulatory mechanisms [48]. The challenge for the future is to gain further insight into the dynamic interplay among the various fatty acid species and their metabolites with other biological molecules, especially proteins and their functioning [49]. The latter includes not only fatty acids interacting with proteins, but also fatty acid-modification of proteins, e.g., posttranslational $N$-myristoylation [50], which adds another level of functionality to many proteins. In addition, specific fatty acid species in lipid bilayers may influence the micro-environment of membrane proteins thereby enhancing or decreasing their functioning.

The complexity of such future studies can be illustrated for the transmembrane protein CD36. As outlined above, CD36 plays a pivotal role in the mechanism and regulation of long-chain fatty acid uptake into several tissues, and is implicated directly in high 
fat diet-induced lipid accumulation in heart and muscle and its progression towards insulin resistance and type 2 diabetes [18]. Inhibition of CD36 was found to prevent cardiac lipotoxicity and insulin resistance as this intervention redirects fatty acid fluxes in the body, thus identifying CD36 as a promising therapeutic target for such chronic lipid metabolic disorder. However, the plasmalemmal presence and proper functioning of CD36 are essential for the beneficial health effects of n-3 LC-PUFAs as the cellular uptake of these fatty acid species is also facilitated by CD36 (Y. Angin, J.J.F.P. Luiken et al., unpublished observations). Furthermore, CD36 has two palmitoylation sites each on both the $N$-terminal and $C$-terminal (cytoplasmic) tails of the protein, which function in its membrane anchoring and proper physiological functioning [51] in addition to the post-translational modifications ( $N$-glycosylation and ubiquitination) mentioned above [19-21]. Finally, the membrane micro-environment, determined a.o. by the fatty acid composition of the constituent phospholipids, will also impact upon CD36 functioning [36]. Taken together, pharmacological inhibition of CD36 may not only prevent the detrimental effects of excess fatty acid uptake but may also limit the beneficial effects of n-3 LC-PUFAs. Hence, future studies should be aimed at finetuning the plasmalemmal functioning of CD36 so as to maintain a proper balance in these various processes.

Taken together and in view of the central roles of fatty acids as signaling and regulatory molecules, fatty acid metabolism and functionality will remain an area of broad interest. New scientific knowledge in this field is expected to have implications in, among others, human development, genetic diversity, and chronic disease prevention. The series of meetings on Fatty Acids in Cell Signaling (FACS) will continue to provide a forum for in-depth discussions in this exciting area (cf. [52]).

\section{References}

[1] E.A. Nunez, Preface - fatty acids and cell signalling, Prostaglandins, Leukot Essent. Fatty Acids 48 (1993) 1-4.

[2] I. Oransky, Obituary of David F. Horrobin, Lancet 361 (2003) 1395

[3] H.A. Bern, Hormones and endocrine glands of fishes. Studies of fish endocrinology reveal major physiologic and evolutionary problems, Science 158 (1967) 455-462.

[4] H.M. Sinclair, Deficiency of essential fatty acids and atherosclerosis, etc. Lancet 270 (1956) 381-383.

[5] D.F. Horrobin, Interactions between n-3 and n-6 essential fatty acids (EFAs) in the regulation of cardiovascular disorders and inflammation, Prostaglandins, Leukot. Essent. Fatty Acids 44 (1991) 127-131.

[6] D.F. Horrobin, Nutritional and medical importance of gamma-linolenic acid, Prog. Lipid Res. 31 (1992) 163-194.

[7] J.F.C. Glatz, G.J. Van der Vusse, Cellular fatty acid-binding proteins: their function and physiological significance, Prog. Lipid Res. 35 (1996) 243-282.

[8] J. Storch, A.E. Thumser, Tissue-specific functions in the fatty acid-binding protein family, J. Biol. Chem. 285 (2010) 32679-32683.

[9] R.L. Smathers, D.R. Petersen, The human fatty acid-binding protein family: evolutionary divergences and functions, Hum. Genome 5 (2011) 170-191.

[10] H. Vorum, R. Brodersen, U. Kragh-Hansen, A.O. Pedersen, Solubility of longchain fatty acids in phosphate buffer at pH 7.4, Biochim. Biophys. Acta 1126 (1992) 135-142.

[11] G.V. Richieri, A.M. Kleinfeld, Unbound free fatty acid levels in human serum J. Lipid Res. 36 (1995) 229-240.

[12] M.M. Vork, J.F.C. Glatz, G.J. Van der Vusse, On the mechanisms of long chain fatty acid transport in cardiomyocytes as facilitated by cytoplasmic fatty acidbinding protein, J. Theor. Biol. 160 (1993) 207-222.

[13] J.F.C. Glatz, J.J.F.P. Luiken, F.A. Van Nieuwenhoven, G.J. Van der Vusse, Molecular mechanism of cellular uptake and intracellular translocation of fatty acids, Prostaglandins, Leukot. Essent. Fatty Acids 57 (1997) 3-9.

[14] J.J.F.P. Luiken, D.P.Y. Koonen, W.A. Coumans, M.M.A.L. Pelsers, B. Binas, A. Bonen, J.F.C. Glatz, Long-chain fatty acid uptake by skeletal muscle is impaired in homozygous, but not heterozygous, heart-type-FABP null mice Lipids 38 (2003) 491-496.

[15] A. Bonen, A. Chabowksi, J.J.F.P. Luiken, J.F.C. Glatz, Mechanisms and regulation of protein-mediated cellular fatty acid uptake: molecular, biochemical and physiological evidence, Physiology 22 (2007) 15-28.

[16] J.A. Hamilton, New insights into the roles of proteins and lipids in membrane transport of fatty acids, Prostaglandins, Leukot. Essent. Fatty Acids 77 (2007) 355-361.
[17] F. Zhang, F. Kamp, J.A. Hamilton, Dissociation of long and very long fatty acids from phospholipid bilayers, Biochemistry 35 (1996) 16055-16060.

[18] J.F.C. Glatz, J.J.F.P. Luiken, A. Bonen, Membrane fatty acid transporters as regulators of lipid metabolism: implications for metabolic disease, Physiol. Rev. 90 (2010) 367-417.

[19] B. Lauzier, C. Merlen, F. Vaillant, J. McDuff, B. Bouchard, P.C. Beguin V.W. Dolinsky, S. Foisy, L.R. Villeneuve, F. Labarthe, J.R.B. Dyck, B.C. Allen, G. Charron, C. Des Rosiers, Post-translocational modifications, a key process in CD36 function: lessons from the spontaneously hypertensive rat heart, J. Mol. Cell. Cardiol. 51 (2011) 99-108.

[20] J. Smith, X. Su, R. El-Maghrabi, P.D. Stahl, N.A. Abumrad, Oppositie regulation of CD36 ubiquitination by fatty acids and insulin, J. Biol. Chem. 283 (2008) $13578-13585$.

[21] K.-Y. Kim, M.V. Stevens, M.H. Akter, S.E. Rusk, R.J. Huang, A. Cohen, A. Noguchi, D. Springer, A.V. Bocharov, T.L. Eggerman, D.-F. Suen, R.J. Youle, M. Amar, A. T. Remaley, M.N. Sack, Parkin is a lipid-responsive regulator of fat uptake in mice and mutant human cells, J. Clin. Investig. 121 (2011) 3701-3712.

[22] A. Chabowksi, J. Gorksi, J.F.F.P. Luiken, J.F.C. Glatz, A. Bonen, Evidence for concerted action of FAT/CD36 and FABPpm to increase fatty acid transport across the plasma membrane, Prostaglandins, Leukot. Essent. Fatty Acids 77 (2007) 345-353.

[23] D.C. Clarke, D. Miskovic, X.X. Han, J. Calles-Escandon, J.F.C. Glatz, J.J.F.P. Luiken, J.J. Heikkila, A. Bonen, Overexpression of membrane associated fatty acid binding protein (FABPpm) in vivo increases fatty acid sarcolemmal transport and metabolism, Physiol. Genomics 17 (2004) 31-37.

[24] M. Kazantzis, A. Stahl, Fatty acid transport proteins, implications in physiology and diseases, Biochim. Biophys. Acta 1821 (2012) 852-857.

[25] J. Kerner, C. Hoppel, Fatty acid import into mitochondria, Biochim. Biophys. Acta 1486 (2000) 1-17.

[26] J.J.F.P. Luiken, H.E.C. Niessen, S.L.M. Coort, N. Hoebers, W.A. Coumans, R.W. Schwenk, A. Bonen, J.F.C. Glatz, Etomoxir-induced partial carnitine palmitoyltransferase-I (CPT-I) inhibition in vivo does not alter cardiac longchain fatty acid uptake and oxidation rates, Biochem. J. 419 (2009) 447-455.

[27] L.C. Heather, K.M. Pates, H.J. Atherton, M.A. Cole, D.R. Ball, R.D. Evans, J.F. C. Glatz, J.J.F.P. Luiken, J.L. Griffin, K. Clarke, Differential translocation of the fatty acid transporter, FAT/CD36, and the glucose transporter, GLUT4, coordinates changes in cardiac substrate metabolism during ischemia and reperfusion, Circ. Heart Fail. 6 (2013) 1058-1066.

[28] E. Kassi, P. Pervanidou, G. Kaltsas, G. Chrousos, Metabolic syndrome: definitions and controversies, BMC Med. 9 (2011) 48.

[29] M. Furuhashi, G.S. Hotamisligil, Fatty acid-binding proteins: role in metabolic diseases and potential as drug targets, Nat. Rev. 7 (2008) 489-503.

[30] R.L.C. Hoo, I.P.C. Lee, M. Zhou, J.Y.L. Wong, X. Hui, A. Xu, K.S.L. Lam, Pharmacological inhibition of adipocyte fatty acid binding protein alleviates both acute liver injury and non-alcoholic steatohepatitis in mice, J. Hepatol. 58 (2013) 358-364.

[31] W.C. Stanley, F.A. Recchia, G.D. Lopaschuk, Myocardial substrate metabolism in the normal and failing heart, Physiol. Rev. 85 (2005) 1093-1129.

[32] A.N. Carley, D.L. Severson, Fatty acid metabolism is enhanced in type 2 diabetic haearts, Biochim. Biophys. Acta 1734 (2005) 112-126.

[33] D.M. Ouwens, M. Diamant, M. Fodor, D.D.J. Habets, M.M.A.L. Pelsers, M. El Hasnaoui, Z.C. Dang, C.E. van den Brom, R. Vlasblom, A. Rietdijk, C. Boer S.L.M. Coort, J.F.C. Glatz, J.J.F.P. Luiken, Cardiac contractile dysfunction in insulin-resistant rats fed a high-fat diet is associated with elevated CD36mediated fatty acid uptake and esterification, Diabetologia 50 (2007) 1938-1948.

[34] D.B. Savage, K.F. Petersen, G.I. Shulman, Disordered lipid metabolism and the pathogenesis of insulin resistance, Physiol. Rev. 87 (2007) 507-520.

[35] Y. Angin, L.K.M. Steinbusch, P.J. Simons, S. Greulich, N.T.H. Hoebers, K. Douma, M.A.M.J. Van Zandvoort, W.A. Coumans, W. Wijnen, M. Diamant, D.M. Ouwens, J.F.C. Glatz, J.J.F.P. Luiken, CD36 inhibition prevents lipid accumulation and contractile dysfunction in rat cardiomyocytes, Biochem. J. 448 (2012) 43-53.

[36] J.F.C. Glatz, Y. Angin, L.K.M. Steinbusch, R.W. Schwenk, J.J.F.P. Luiken, CD36 as target to prevent cardiac lipotoxicity and insulin resistance, Prostaglandins, Leukot. Essent. Fatty Acids 88 (2013) 71-77.

[37] A. Geloen, L. Helin, B. Geeraert, E. Malaud, P. Holvoet, G. Marguerie, CD36 inhibitors reduce postprandial hypertriglyceridemia and protect against diabetic dyslipidemia and atherosclerosis, PloS One 7 (2012) e37633.

[38] V.L. Bessi, S.M. Labbé, D.N. Huynh, L. Ménard, C. Jossart, M. Febbraio, B. Guérin, M. Bentourkia, R. Lecomte, A.C. Carpentier, H. Ong, S. Marleau, EP 80317, a selective CD36 ligand, shows cardioprotective effects against post-ischaemic myocardial damage in mice, Cardiovasc. Res. 96 (2012) 99-108.

[39] S. Lorente-Cebrián, A.G.V. Costa, S. Navas-Carretero, M. Zabala, J.A. Martínez, M.J. Moreno-Aliaga, Role of omega-3 fatty acids in obesity, metabolic syndrome, and cardiovascular diseases: a review of the evidence, J. Physiol. Biochem. 69 (2013) 633-651.

[40] P. Saravanan, N.C. Davidson, E.B. Schmidt, P.C. Calder, Cardiovascular effects of marine omega-3 fatty acids, Lancet 376 (2010) 540-550.

[41] J.X. Kang, Dr. Alexander Leaf, an exemplary physian-scientist and a great man, Prostaglandins, Leukot. Essent. Fatty Acids 88 (2013) 197-199.

[42] J.X. Kang, A. Leaf, Prevention of fatal cardiac arrhythmias by polyunsaturated fatty acids, Am. J. Clin. Nutr. 71 (2000) S202-S207.

[43] A. Leaf, C.M. Albert, M. Josephson, D. Steinhaus, J. Kluger, J.X. Kang, B. Cox, H. Zhang. D. Schoenfeld, Prevention of fatal arrhythmias in high-risk subjects by fish oil n-3 fatty acid intake, Circulation 112 (2005) 2762-2768.

[44] M.H. Raitt, W.E. Connor, C. Morris, J. Kron, B. Halperin, S.S. Chugh, J. McClelland, J. Cook, K. MacMurdy, R. Swenson, S.L. Connor, G. Gerhard 
D.F. Kraemer, D. Oseran, C. Marchant, D. Calhoun, R. Shnider, J. McAnulty, Fish oil supplementation and risk of ventricular tachycardia and ventricular fibrillation in patients with implantable defibrillators, J. Am. Med. Assoc. 293 (2005) 2884-2891.

[45] A.C. Höper, W. Salma, S.J. Sollie, A.D. Hafstad, J. Lund, A.M. Khalid, J. Raa, E. Aasum, T.S. Larsen, Wax esters from the marine copecod Calanus finmarchicus reduce diet-induced obesity and obesity-related metabolic disorders in mice, J. Nutr. 144 (2014) 164-169.

[46] G.D. Lawrence, Dietary fats and health: dietary recommendations in the context of scientific evidence, Adv. Nutr. 4 (2013) 294-302.

[47] J.B. German, C.J. Dillard, Saturated fats: what dietary intake? Am. J. Clin. Nutr. 80 (2004) 550-559.

[48] R.A. Waterland, M.-T. Rached, Developmental establishment of epigenotype: a role for dietary fatty acids? Scand. J. Food Nutr. 50 (S2) (2006) 21-26.
[49] J.F.C. Glatz, Challenges in fatty acid and lipid physiology, Front. Fatty Acid Lipid Physiol. 2 (2011) 1-3.

[50] D.D.O. Martin, E. Beauchamp, L.G. Berthiaume, Post-translational myristoylation: fat matters in cellular life and death, Biochimie 93 (2011) 18-31.

[51] M.M. van Oort, R. Drost, L. Janssen, J.M. van Doorn, J. Kerver, D.J. van der Horst, J.J.F.P. Luiken, C.W. Rodenburg, Each of the four intracellular cysteines of CD36 is essential for insulin- or AMP-activated protein kinase-induced CD36 translocation, Arch. Physiol. Biochem. 120 (2014) 40-49.

[52] J.T. Brenna, N.G. Bazan, P.C. Calder, S.C. Cunnane, Docosahexaenoic acid in translational medicine: the tenth fatty acids in cell signaling meeting (FACS-10), Prostaglandins, Leukot. Essent. Fatty Acids 88 (2013) 1-146. 